\title{
Impact of protocol-based guidelines on the management and outcome of acute upper gastrointestinal hemorrhage in a district general hospital
}

\author{
RM Anwar FRCS RAMC, A Dhanji MRCS, A Fish, S Singh FRCS
}

\begin{abstract}
RM A nwar, A Dhanji, A Fish, S Singh. Impact of protocolbased guidelines on the management and outcome of acute upper gastrointestinal hemorrhage in a district general hospital. C an J G astroenterol 2003;17(2):97-100.
\end{abstract}

A prospective audit of acute upper gastrointestinal ( $\mathrm{GI}$ ) hemorrhage was conducted between January and September 2000 at Frimley Park $\mathrm{H}$ ospital to determine the impact of introducing an upper GI bleeding protocol based on Rockall's initial risk scoring system.

Fifty-seven patients and 52 patients were in the pre- and postprotocol phases of the study respectively. Fifty per cent (28) of the patients in the first phase and $40 \%$ (21) of the patients in the second phase belonged to the high risk group. In the preprotocol phase, endoscopy was performed in $86 \%$ (49) of cases with $60 \%$ of patients having an esophogastroduodenoscopy within $24 \mathrm{~h}$. Thirty-three per cent of the high risk group failed to have an endoscopic examination within $24 \mathrm{~h}$. O nly two of 57 patients required surgery and the mortality was $14 \%$. In the postprotocol phase, endoscopy was performed in $79 \%$ (42) of patients and 68\% (36) patients had endoscopy within $24 \mathrm{~h}$. 0 nly four of 21 patients belonging to the high risk group had their endoscopy after $24 \mathrm{~h}$ of the admission. Patients were better monitored and mortality was reduced to $7.5 \%$. Reduction of mortality from upper GI hemorrhage followed the introduction of an agreed protocol based on risk scoring

Key W ords: A udit; Risk scoring; U pper gastrointestinal bleeding

Most audits of acute upper gastrointestinal (GI) hemorW rhage usually involve an initial retrospective study to determine the management and outcome, followed by a prospective analysis that attempts to ascertain the impact of specific alteration in clinical practice, making comparison complex and unreliable (1). A prospective audit was started at Frimley Park Hospital (FPH), U nited Kingdom, in January 2000.

The purpose of the audit is:

- To establish the current practice and outcome of upper GI hemorrhage in FPH .

- To introduce protocol, educate and train the health care professionals involved.

- A ssess the impact of protocol on practice and outcome.

\author{
Les répercussions de directives fondées sur des \\ protocoles sur la prise en charge et l'issue d'une \\ hémorragie gastro-intestinale supérieure aiguë dans un \\ hôpital général de district
}

\begin{abstract}
Une vérification prospective d'hémorragies gastro-intestinales (GI) supérieures a été menée entre janvier et septembre 2000 au F rimley Park H ospital afin de déterminer les répercussions de l'implantation d'un protocole sur les saignements $\mathrm{GI}$ supérieurs d'après le système de pointage du risque initial de Rockall.

Cinquante-sept patients ont participé à la phase préprotocole de l'étude, tandis que 52 ont participé à la phase postprotocole. Cinquante pour cent (28) des patients de la première phase et $40 \%$ (21) de ceux de la deuxième phase faisaient partie du groupe à haut risque. Pendant la phase préprotocole, une endoscopie a été exécutée dans $86 \%$ (49) des cas, et $60 \%$ de ces patients ont subi une œsophagogastroduodénoscopie dans un délai de 24 heures. Trente-trois pour cent du groupe à haut risque n'ont pas subi d'endoscopie dans un délai de 24 heures. Seulement deux des 57 patients ont dû se faire opérer, et le taux de mortalité s'est élevé à $14 \%$. Pendant la phase postprotocole, une endoscopie a été exécutée chez $79 \%$ (42) des patients, et $68 \%$ (36) ont subi une endoscopie dans un délai de 24 heures. Seulement quatre des 21 patients faisant partie du groupe à haut risque ont subi leur endoscopie plus de 24 heures après leur hospitalisation. Les patients étaient mieux surveillés, et le taux de mortalité a chuté à 7,5\%. La réduction du taux de mortalité découlant d'une hémorragie GI supérieure a fait suite à l'implantation d'un protocole consensuel fondé sur un indice élevé.
\end{abstract}

The first phase of the audit to assess the management and outcome of upper GI hemorrhage was completed in A pril 2000. $A n$ agreed protocol on the management of patients with upper GI hemorrhage at FPH was drawn up in light of the findings of the first phase of the audit. The health care professionals involved with care of such patients had been instructed and informed of the protocol. The protocol involved management guidelines for patients with upper $\mathrm{G}$ I hemorrhage. A ny change in practice and outcome following the introduction of the protocol was monitored through the second phase of the prospective audit, which was completed in September 2000.

\section{MATERIALS AN D METHODS}

A II patients admitted with a presumptive diagnosis of upper $\mathrm{GI}$ hemorrhage or all patients who bled acutely from the upper GI tract while in hospital for treatment of some other condition at

F rimley Park H ospital, Portsmouth Road, Frimley, C amberley, Surrey, U nited Kingdom

C orrespondence: M ajor RM A nwar, A rmy M edical Directorate, Slim Road, C amberley, Surrey G U 15 4N P, U nited Kingdom.

Telephone +0044-7818402781, fax +0065-67227356, e-mail raqibanwar@hotmail. com

Received for publication A pril 30, 2002. A ccepted N ovember 18, 2002 


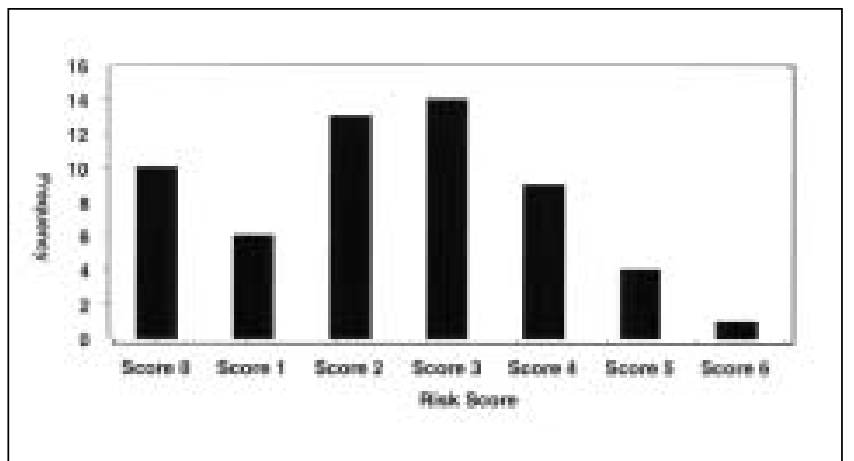

Figure 1) Frequency of risk score in the first phase. F ifty per cent had risk score of $2+$

FPH between January and A pril 2000 and then between June to September 2000 were included in the study. A II patients had historical and/or clinical evidence of hematemesis and/or melena. $\mathrm{U}$ pper $\mathrm{GI}$ hemorrhage has been defined in this study as vomit containing red blood (or coffee ground like material, observed by a doctor or a nurse), and/or the stool has been black or red-black confirmed by observation or rectal examination.

Patients were identified using the surgical admission database and by questioning the teams on call for emergency admission on a daily basis.

Data were collected by the completion of two separate proformas: an upper GI bleed endoscopy form, that specified esophogastroduodenoscopy (EGD) and its findings; and an upper GI bleed general form, specific to the management and outcome of upper GI hemorrhage.

Data were collected on age and sex distribution, risk factors, $H$ igh Dependency U nit (H DU) admission, monitoring and record keeping. Data collected on endoscopy involved time of endoscopy, grade (seniority) of endoscopist and therapeutic intervention carried out. Data were also collected on surgical intervention, morbidity and inhospital mortality.

Risk score was assessed once data were available using Rockall'sinitial risk scoring system (2). T his system, although very simplistic, is reproducible. It involves an additive score of the number of important risk factors. The risk factors are age over 60 years, systolic blood pressure of less than $100 \mathrm{mmH} \mathrm{g}$, hemoglobin less than $10 \mathrm{~g} / \mathrm{dL}$, any major comorbidity, a diagnosis of upper $\mathrm{G}$ । malignancy or varices, the presence of stigmata of recent hemorrhage and rebleeding.

\section{D emographic data}

\section{RESU LT S}

First phase: Fifty-seven patients had a presumptive diagnosis of upper $\mathrm{GI}$ hemorrhage during the study period. Their mean age was 69 years and median of 76 years, range 16 to 95 years, with a male to female ratio of 3:2.

Second phase: Fifty-two patients were admitted with a diagnosis of upper $\mathrm{GI}$ bleed. Their mean age was 62 years, median age 69 years and mode 81 years with a range of 15 to 92 years.

\section{R isk score, blood transfusion and monitoring}

First phase: Twenty-eight (50\%) patients belonged to the high risk group (risk factor $2+$ ) (Figure 1 ). N one of the patients was admitted to the HDU after the initial assessment. Twenty-

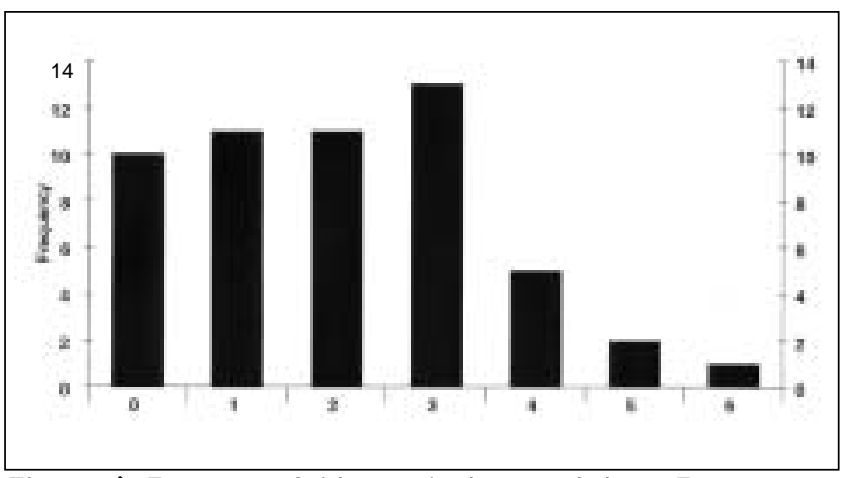

Figure 2) Frequency of risk score in the second phase. Forty per cent had risk score of $2+$

nine $(51 \%)$ patients received blood transfusion in whom 24 $(42 \%)$ had documented urinary output monitoring. Central venous pressure monitoring was used only in six (10\%) patients.

Second phase: Twenty-one patients (40\%) belonged to the high risk group (Figure 2). In this phase of the study one patient was admitted in the intensive care unit (ICU) and one patient in the HDU. Twenty-nine (55\%) received blood transfusion, four $(7.5 \%)$ patients had central venous pressure monitoring and 46 (87\%) patients had documented urinary output monitoring

\section{Endoscopy}

First phase: Eighty-six per cent (49) of all patients underwent endoscopy some time during their admission. Of the eight patients who did not have an EGD, three refused endoscopic examination, two were young and stable and had a questionable diagnosis of upper GI bleed, one had EGD planned but died of a cerebrovascular accident and two had suspected $M$ allory-W eiss tears and no endoscopic examination was contemplated. Thirty-four (60\%) patients had an EGD within $24 \mathrm{~h}$ and $22 \%$ had an EGD outside of normal working hours. Eleven $(33 \%)$ of the high risk group failed to have an endoscopic examination within $24 \mathrm{~h}$. Consultants/staff grade carried out endoscopy in 17 patients whereas in 32 patients special ist registrars performed the endoscopy. A II endoscopies were performed by a surgeon. Twenty patients had therapeutic procedures at endoscopy and there were no complications from EGD.

Second phase: Forty-two patients (79\%) had an upper GI endoscopy while inpatients in this admission. Four patients were deemed to have a minor bleed and were discharged home after observation with an outpatient endoscopy arranged, two patients were medically unfit to have an endoscopy and one patient refused to undergo an endoscopy. O ne patient, a pregnant woman, had a doubtful history of hematemesis and was only observed. Two patients were admitted with coffee ground vomit with a history of peptic ulcer disease, and in addition had small bowel obstruction.

Thirty-six patients (68\%) had an EGD within $24 \mathrm{~h}$ of admission. Only four of 21 high risk patients had endoscopy after $24 \mathrm{~h}$ of their admission. Thirteen patients (24.5\%) had therapeutic intervention at endoscopy. C onsultant /staff grade 
surgeons performed endoscopy in 31 patients whereas specialist registrars carried out endoscopy on 11 patients. Endoscopy was not associated with any complication.

\section{Surgery}

First phase: Two patients, both males over the age of 75 years with a risk score of more than four, required surgery. They had diagnostic and therapeutic endoscopies within $24 \mathrm{~h}$ of admission and were each found to have a duodenal ulcer. Both required a second therapeutic EGD for rebleed and had oversewing of the bleeding ulcer at surgery. They were admitted to the HDU. O ne of them had severe respiratory comorbidity and died from respiratory failure postoperatively. The second patient was successfully discharged home three weeks after surgery.

Second phase: Two patients had surgery. A 15-year-old girl had collapsed secondary to a bleeding vascular malformation in the duodenum. Therapeutic intervention at endoscopy failed to stop the bleeding. U nder-running of the vascular malformation was done at surgery. The other patient, a medical inpatient, had hematemesis from a gastric carcinoma diagnosed at endoscopy. A t surgery he was found to have an inoperable gastric cancer. The patient was kept comfortable and died postoperatively.

\section{M ortality}

First phase: Eight (14\%) patients in the study died in hospital and/or within 30 days. They were all over the age of 79 years. Their average age was 87.5 years, median age 88 years with a range of 79 to 95 years. One refused any active intervention. Three suffered cerebrovascular accident before any therapeutic measures were instituted. One died postoperatively from respiratory failure. 0 ne had a myocardial infarction, one died of pneumonia and the other of multiorgan failure. The case notes of all the patients were carefully reviewed and it was concluded that their deaths were not preventable.

Second phase: 0 nly four patients (7.5\%) died during the second phase. One has been mentioned above. The second patient was a 33-year-old female patient admitted with coffee ground vomiting. Endoscopy was normal. Computed tomography revealed a brain tumour from which she succumbed. A 92year-old gentleman, known to suffer from carcinoma of the esophagus, had a hematemesis. He was unfit for an EGD and subsequently died. A nother, an 89-year-old man had a bleeding gastric ulcer seen on EG D that was injected. $\mathrm{H}$ e continued to bleed. He was unfit for surgery and was kept comfortable.

\section{DISC U SSION}

The agreed protocol used in the study was based on the guidelines for good practice in the management of upper $\mathrm{GI}$ hemorrhage recommended by the joint working group of the British Society of Gastroenterology, the Research U nit of the Royal College of Physicians of London and the A udit Unit of the Royal C ollege of Surgeons of England (3).

Risk score in this study was assessed using Rockall's risk scoring system $(2,4)$. Rockall's risk scoring system primarily allows determining case mix and calculating risk-standardized
TABLE 1

Diagnoses of phase one patients

\begin{tabular}{lc}
\hline Diagnosis & $\mathbf{n}$ \\
\hline Esophagitis & 4 \\
Barrett's esophagus & 4 \\
Esophageal varices & 1 \\
Esophageal tumour & 1 \\
Esophageal ulcer & 5 \\
Gastritis & 10 \\
Gastric ulcer & 7 \\
Gastric tumour & 1 \\
Gastric erosions & 1 \\
Gastric polyps & 1 \\
Pyloric stenosis & 1 \\
Duodenitis & 3 \\
Duodenal ulcer & 9 \\
Hiatus hernia & 6 \\
Anastomotic ulcer & 1 \\
Mallory-Weiss tear & 2 \\
Normal & 6 \\
\hline
\end{tabular}

TABLE 2

Diagnoses of phase two patients

\begin{tabular}{ll}
\hline Diagnosis & $\mathbf{n}$ \\
\hline Esophagitis & 11 \\
Gastritis & 16 \\
Duodenitis & 6 \\
Esophageal ulcer & 6 \\
Gastric ulcer & 12 \\
Duodenal ulcer & 8 \\
Esophageal malignancy & 2 \\
Gastric malignancy & 2 \\
Duodenal malignancy & 1 \\
Esophageal varices & 6 \\
Gastric varices & 1 \\
Hemobilia & 1 \\
Mallory-Weiss tear & 1 \\
Erosions & 1 \\
Stomal ulcer & 1 \\
Bleeding disorder & 2 \\
Polyp & 4 \\
Normal & 7
\end{tabular}

mortality. The system has also been proven to predict outcome in patients presenting with upper GI hemorrhage $(5,6)$. Blatchford et al (7) recently developed a risk scoring system to predict and identify patients' need for treatment in upper GI hemorrhage, though the system requires external validation.

Twenty-two patients during the first phase of the study and 27 patients during the second phase were found to have peptic ulcer disease (Tables 1 and 2). These findings show that bleeding from a peptic ulcer is still the most common cause of upper GI hemorrhage despite the widespread availability of effective antiulcer drugs. Peptic ulcer disease is responsible for nearly $50 \%$ of cases of severe upper $\mathrm{GI}$ hemorrhage (8).

In the majority of the patients with an upper GI hemorrhage, the bleeding stops spontaneously. Patients with contin- 
ued or recurrent bleeding remain a therapeutic challenge. Therapeutic endoscopy constitutes the cornerstone of modern therapy of these patients. Over half of these patients will respond to endoscopic treatment with injection, thermocoagulation or laser (9). Twenty of 57 patients in the first phase and 13 of 53 patients in the second phase of the study had an injection of adrenaline at endoscopy. This high incidence of injection therapy may explain the very small number of patients requiring surgery. The incidence of surgical intervention was much lower than that in the N ational upper $\mathrm{GI}$ hemorrhage audit. A total of 181 of $2332(7.8 \%)$ in the first phase and 111 of $1625(6.8 \%)$ in the second phase of the national audit of acute upper GI hemorrhage had surgical intervention (2). Liberal use of endoscopic injection therapy is known to be associated with a low operation rate (10).

A dditional therapeutic options in upper $\mathrm{GI}$ hemorrhage are based on in vitro experiments showing the $\mathrm{pH}$ dependence of the coagulation mechanism. The lower the $\mathrm{pH}$, the worse the platelet aggregation and the plasma coagulation, and at a pH below four the fibrin in the clot is dissolved by the proteolytic action of pepsin. Stabilization of the clot consequent on increasing the gastric $\mathrm{pH}$, in theory, therefore, could reduce bleeding or prevent its recurrence. The role of various agents reducing gastric acidity has been explored to achieve such a goal. Trials with $\mathrm{H}_{2}$ receptor antagonists have failed to demonstrate a consistent significant therapeutic benefit. A Ithough they are effective in heal ing peptic ulcer disease, they have not been shown consistently to reduce the incidence of continued or recurrent bleeding or the need for surgical interventions in patients with acute upper GI hemorrhage. H owever, available data on proton pump inhibitors, which profoundly suppress acid production and secretion, are suggestive but not conclusive that they may decrease the overall incidence of rebleed and the need of surgery in select patients with acute upper G I hemorrhage (9).

$\mathrm{H}$ igh dependency care and close monitoring with central venous pressure recording appears to have been used sparingly during the first phase of the study. $\mathrm{N}$ o patient was admitted to the HDU/ITU after initial assessment and, overall, only $10 \%$ of the patients had achieved monitoring of central venous pressure during this phase. Twenty-four patients (42\%) had been monitored by urinary output measurement. During the second phase two patients were admitted to the HDU/ITU and $6 \%$ of the patients had central venous pressure monitoring. H owever, 46 patients (87\%) had documented urinary monitoring during this phase of the study.

The impact of management of patients with upper $\mathrm{GI}$ bleeding, in the HDU with agreed management protocol and close monitoring, on mortality appears to be somewhat contradictory. Masson et al (11) reports a significantly low mortality rate when patients are cared for in dedicated units with specialized staff and close monitoring. Kapur et al (10), on the other hand, failed to demonstrate any reduction in mortality from upper $\mathrm{GI}$ hemorrhage following the introduction of $\mathrm{HDU}$ care and agreed protocol.

In the first phase of this study eight ( $14 \%$ ) patients, all over the age of 79 years, died. Their average age was 87.5 years with a range of 79 to 95 years. A dvanced age is a well known signif- icant risk factor in upper $\mathrm{GI}$ hemorrhage for rebleeding and death. $M$ ortality from upper $G I$ hemorrhage increases from less than $10 \%$ in those patients below the age of 60 years to $35 \%$ in patients over the age of 80 years $(12,13)$. When a study involves an elderly population with severe concurrent disease, reduction in mortality is difficult to achieve (11).

M ortality was reduced from $14 \%$ in the first phase to $7.5 \%$ in the second phase of the study. Though this reduction is not statistically significant, this study has demonstrated a trend in reduction in mortality. The reduction in mortality achieved may have been due to the introduction of agreed protocol and closer patient monitoring and early endoscopic intervention.

\section{CON CLUSIONS}

O ur prospective audit has demonstrated that a reduction of mortality may be achieved following the introduction of an agreed protocol on the management of patients with upper G I hemorrhage and that evidence-based guidelines should be considered necessary in the management of these patients.

ACKN OWLEDGEMENT: We thank Mr Simon Toh, Consultant Upper Gastrointestinal Surgeon at Queen A lexandra H ospital, Portsmouth for his support.

\section{REFEREN CE}

1. Rockall TA, Logan RFA, Devlin HB, N orthfield TC. Influencing the practice and outcome in acute upper gastrointestinal hemorrhage. Gut 1997;41:606-11.

2. National audit of acute upper gastrointestinal hemorrhage. Confidential report of the second audit. A udit unit, Royal College of Surgeons of England. RCP, London, British Society of G astroenterology and the A SG BI. (A ppendix)

3. G uidelines for good practice in and audit of the management of upper gastrointestinal hemorrhage. Report of a joint working group of the British Society of $G$ astroenterology, the Research U nit of the Royal College of Physicians of London and the A udit U nit of the Royal College of Surgeons of England. J R Coll Physicians Lond 1992;26:281-9.

4. Rockall TA, Logan RFA, Devlin HB, N orthfield TC. Risk assessment after acute upper gastrointestinal hemorrhage. $G$ ut 1996;38:316-21.

5. Church NI, Palmer KR. Relevance of the Rockall score in patients undergoing endoscopic therapy for peptic ulcer hemorrhage. Eur J G astroenterol H epatol 2001;13:1149-52.

6. G oodchap RJ, Sanders DS, C arter MJ, G leeson DC, Lobo A J. Validity of the Rockall risk score for upper gastrointestinal hemorrhage in subgroups of patients with varices and peptic ulcers. G ut 1999;44:94A .

7. Blatchford $O, M$ urray $W R$, Blatchford M . A risk score to predict need for treatment for upper gastrointestinal hemorrhage. Lancet 2000;356:1318-21.

8. Van Dam J, Brugge W R. Endoscopy of the upper gastrointestinal tract. N Engl J Med 1999;341:1738-48

9. Bustamante M, Stollman N. The efficacy of proton-pump inhibitors in acute ulcer bleeding. J C lin G astroenterol 2000;30:7-13

10. Kapur KC, G reen JT, Turner RG, et al. A uditing mortality from upper gastrointestinal hemorrhage: Impact of a high dependency unit. J R C oll Physicians Lond 1998;32:246-50.

11. M asson J, Bramley PN, H erd K, et al. U pper gastrointestinal bleeding in an open-access dedicated unit. J R Coll Physicians Lond 1996;30:436-42.

12. Rosen AM. G astrointestinal bleeding in the elderly. Clin G eriatr M ed 1999;15:511-25.

13. Chow LW C, G ertsch P, Poon RTP, Branicki FJ. Risk factors for rebleeding and death from peptic ulcer in the very elderly. $\mathrm{Br}$ J Surg 1998;85:121-4. 


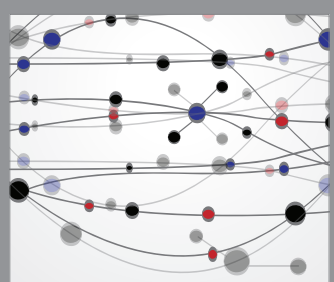

The Scientific World Journal
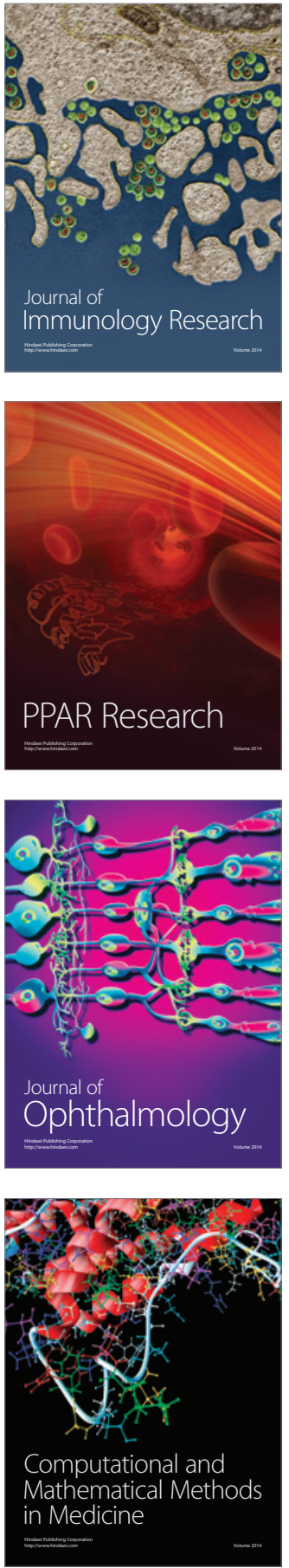

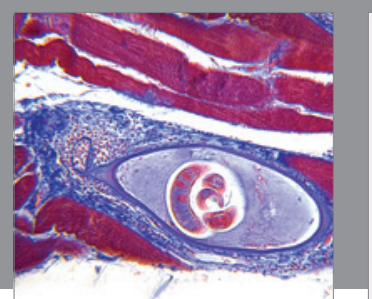

Gastroenterology Research and Practice

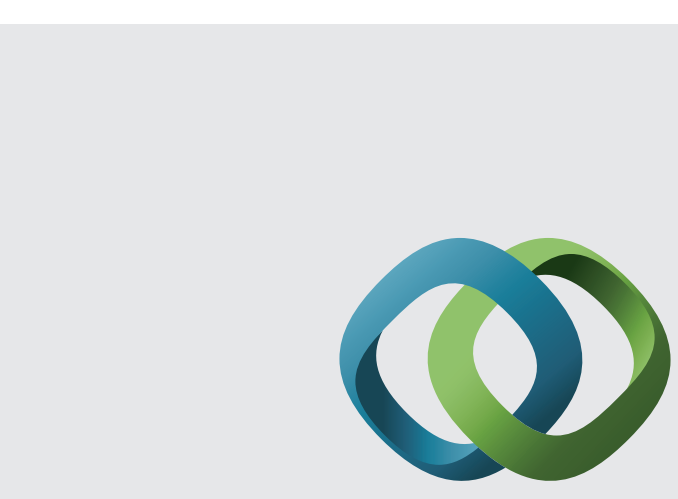

\section{Hindawi}

Submit your manuscripts at

http://www.hindawi.com
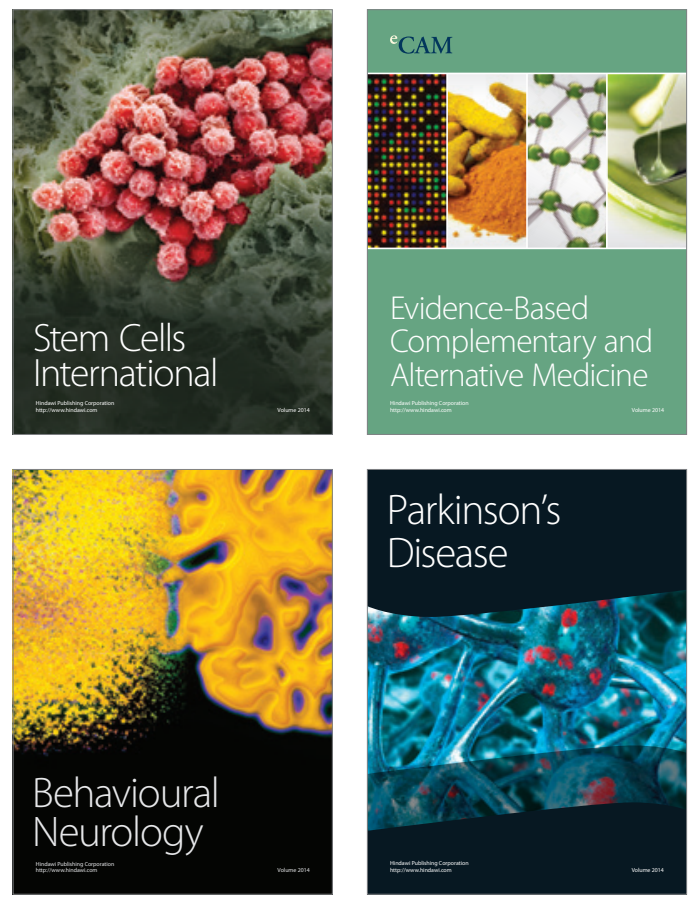
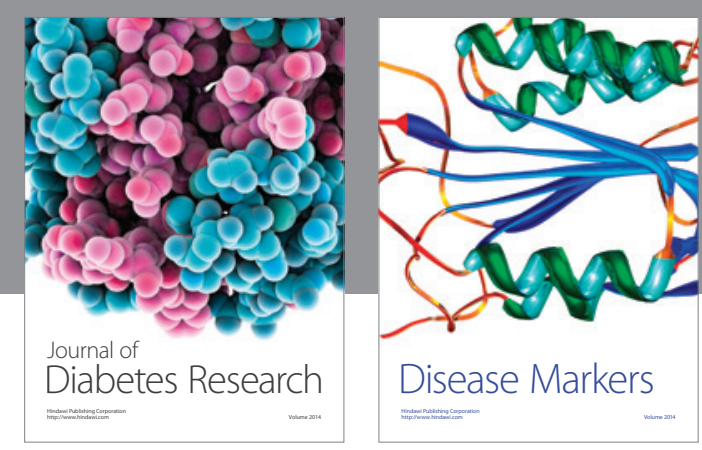

Disease Markers
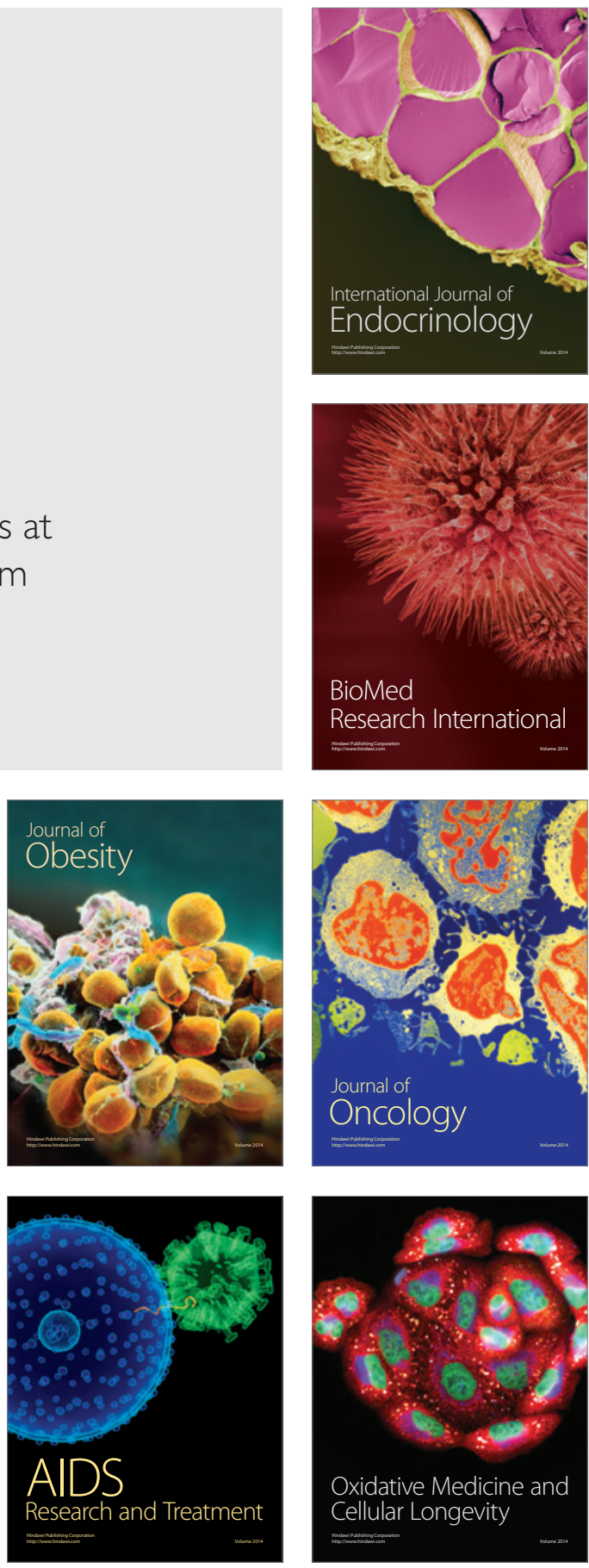